\title{
8 Supplementary Information
}

\subsection{Normal Mode Analysis with the Elastic Network Model}

The function of a protein is determined by its dynamics, not by its static structure alone (62). Protein dynamics are dominated by low frequency collective motions involving large parts of the structure. A popular method to study these coupled motions is normal mode analysis (NMA). NMA assumes at the outset that a harmonic analysis at a single conformational energy minimum can give relevent information on a protein's dynamics. It is based on the diagonalization of the second derivative of the potential energy matrix $(63 ; 64 ; 65 ; 66 ; 67)$. Recent exploitations of NMA have highlighted its usefulness and applicability towards predicting collective, large-scale protein motions that are biologically relevant (see (68) and references therein).

All the normal modes with the Elastic Network Model (ENM) were calculated using the el-Nemo web server (69). The coordinates of the $\mathrm{C}_{\alpha}$ atom for each residue with a 10 $\AA$ cutoff were used to build the elastic network for the crystal structure corresponding to the R-state. The contribution of the normal modes to the conformational change from the R-state to the T-state was calculated by computing the overlap of the eigenvectors of the normal modes to the conformational change between the R-state and the equilibrated structure of the T-state (as the crystal structure of T-state has not yet been resolved). The normal mode analysis indicates that the open/closed transition is dominated by modes 1 and 2, which involve the coupling of motion at the interface between hisF and hisH to that of the loops at the C-terminal active site of hisF (Fig. 11). 


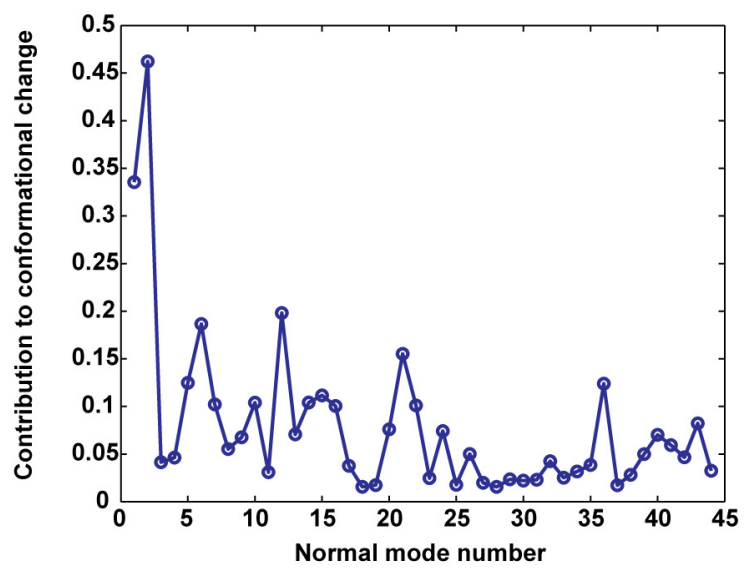

Figure 11: Contribution of normal modes to the conformational transition between the R-state and the T-state.

Normal mode 1 involves the twisting of the interface with hisF and hisH rotating in opposite directions and this twisting is coupled with motion at the active site of hisF. Normal mode 2 couples the breathing motion of the interface to the closing of the loops around the vacant PRFAR binding site at the active site of hisF. 
A) S. oneidensis S. coelicolor

R. sphaeroides

$R$. solanacearum

L. plantarum

T. maritima

S. cerevisiae

A. thaliana

C. caldarium

C. paradoxa

S. solfataricus

S. oneidensis

S. coelicolor

R. sphaeroides

$R$. solanacearum

L. plantarum

T. maritima

S. cerevisiae

A. thaliana

C. caldarium

C. paradoxa

S. solfataricus

S. oneidensis

S. coelicolor

$\boldsymbol{R}$. sphaeroides

$R$. solanacearum

L. plantarum

T. maritima

S. cerevisiae

A. thaliana

C. caldarium

C. paradoxa

S. solfataricus

S. oneidensis

S. coelicolor

$R$. sphaeroides

$R$. solanacearun

L. plantarum

T. maritima

S. cerevisiae

A. thaliana

C. caldarium

C. paradoxa

S. solfataricus

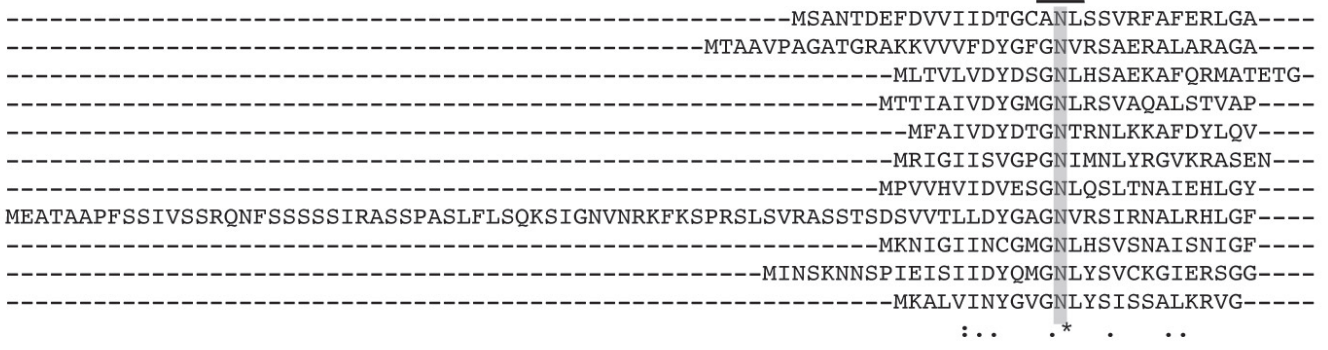

P49 G52

C84

--NVLVTDDKASIK--AAKRVVLPGVGSAGAAMASLTEKA--LVELIOGLT----OPVLGVCLGMOMLTLLSKERGGOALDCOAHDCKCL --DVEITRDYDKAM--NADGLLVPGVGAFAACMEGLKAAR--GDWIVDRRLS-GGRPVMGICVGMOILFSRGIEHDVEA--------EGL AGQVLVSDRPEDVA--RADRIVLPGDGAFPACRRALGSYGGLSEAIEEAVTR-RARPFLGICIGMQMMATRGLEHE---------ETPGF DADVRISAOADEIR--AADRVVLPGOGAMPDCMAAFDOSG--LREAVLEAA--RTKPMLGVCVGEOMLLERSAEARAGE-----AFTAGL --STILTADPOOLA--AADAVILPGVGAFAAAMAALKERO--LVGVLOALAR-SGKPVLGICLGMOLLFESSSEYGEHA---------GL -FEDVSIELVESPRNDLYDLLFIPGVGHFGEGMRRLREND--LIDFVRKHVE-DERYVVGVCLGMQLLFEESEEAPG---------VKGL --EVQLVKSPKDFNISGTSRLILPGVGNYGHFVDNLFNRG--FEKPIREYIE-SGKPIMGICVGLQALFAGSVESPK---------STGL --SIKDVQTPG--DILNADRLIFPGVGAFAPAMDVLNRTG--MAEALCKYIE-NDRPFLGICLGLOLLFDSSEENGP---------VKGI --NPVI INASKDLVSF ACSALVLPGVGSFDLAIDRLEKKN--LIEPVKLWIQ-EDRPFVGICLGLQLLFEGSDEGSK----------PGL --IPKIINSAEEIK--KATALILPGVGSFDPAMKQLKKQD--LINPIKDAIS-EKKPFLGICLGLHLLFEESEEGIE----------SGL -FEVTID-NKPRND---YDLIVFPGVGAFSAVAEF ILRYRELFNDLRRSGTN-----FLGVCLGMQIMFEKGTEGKE---------SNGL

$$
\text { .:* : :* : : . * }
$$

W123
GIIP--TEIDELNSQTLKA---EGLPLPHMGWNQLTFSNP---SQVHPLFAGVEAG---SYVYFVHSYRAPLSDY-----------TLAQ DEWP--GTVGPLEAD----------VVPHMGWNTVEAPAD------SQLFAGLDAD---ARFYFVHSYAVHEWTQESHNPL-----IAEP GWIA--AEVVRIAPS------DPHLKVPHMGWERLTVDHP------HPVLTGIETG---DHAYFVHSYHFOVAHD-------_---AERI GLIS--GDVIRFDLDGRLQPDGSRYKVPQMGWNRVHQSRT------HALWAGVPDQ---SYFYFVHSYYARPAHP-----------DESV GLLS--GRVSALPTDL-------NVKVPQMGWNQNELRRP------D-SPFASIDA---AYTYFVHSYYAVCPAT------------EIV

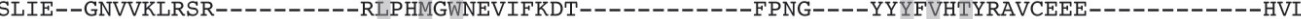
NYID--FKLSRFDDSE--------KPVPEIGWNSCIPS--------ENLFFGLDPY---KRYYFVHSFAAILNSEKKKNLE---NDGWKI GVIP--GIVGRFDASAG-------IRVPHIGWNALQVG-------KDSEILDDVGN---RHVYFVHSYRAIPSDE---------NKDWIS KIFN--GYVSQFKHS-------LVKKVPHMGWNKLYFNRFNTIDNLV GILS--GSVKRIKNE-------PEITIPHMGWNOLOLT-----NPKC GWFK--GIVDKINANV---------KLPHIGWDLVFEVKD-----SC

$$
\text { : : } \quad:{ }^{*} . \text { :** }^{*} \text { : }
$$

CR----YG-EDFSAAIGKDN--FMGVQFHPEKSAAVGAQILGNFLKN. RVTWSTHGKP-FVAAVENGA--LWATQF HPEKSGDAGAQLLTNWIET AH--ADYG-ADITAIVGRDT--MVGTQF HPEKSQKT-AALIANFLTK GE--TEYG-VRFTCAIARDN--IFATOFHPEKSAOAGLQIYRNFVHK AT--VQHG-VQVPSIVQQQ--NVIGMOF HPEKSGRVGLQQLAAFKEN. GT--TEYDGEIFP SAVRKGR--ILGFQF HPEKSSKIGRKLLEKVIEC AK--AKYGSEEFIAAVNKNN--IFATOFHPEKSGKAGLNVIENFLKST--CNYG-ESFISSIRRGN--VHAVQFHPEKSGEVGLSVLRRFLHTTSLTFYGKQKIVSSISYNN--ILATQF HPEKSGLFGLF ILKRFLSS AA--VTHGTOQVTAAIOYEN--ISAVQFHPEKSAS IGLHMLNNFVQC YMK-SQYG-IEYPALVCDKN--VVGTOFHPEKSSNTGKIFLENLKGH

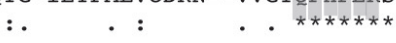

Evolutionary profile of synthase domain and structural alignment.

A) Representative alignment from sequence QR method (1) shows bacteria (blue), eukarya (red), and archaea (green). All available Swiss-Prot sequences of hisH were aligned and then ranked by sequence dependence; $S$. cerevisiae (yeast) and T. maritima were constrained to be the first two in the ordering. Strict conservation is denonted with an * and partial conservation by either ":" or ".". Residues predicted to play a role in the allosteric effect are highlighted according to color scheme in Figure 1, catalytic residues in blue and red. Experimentally mutated residues are underlined. Numbering corresponds to T. maritima.

B) Structural alignment of yeast (red) and T. maritima (blue) crystal structures indicates high structural homology between the two isoforms, despite insertions in yeast. Conserved residues are shown in licorice, and the overall RMSD is $1.86 \mathrm{~A}$.

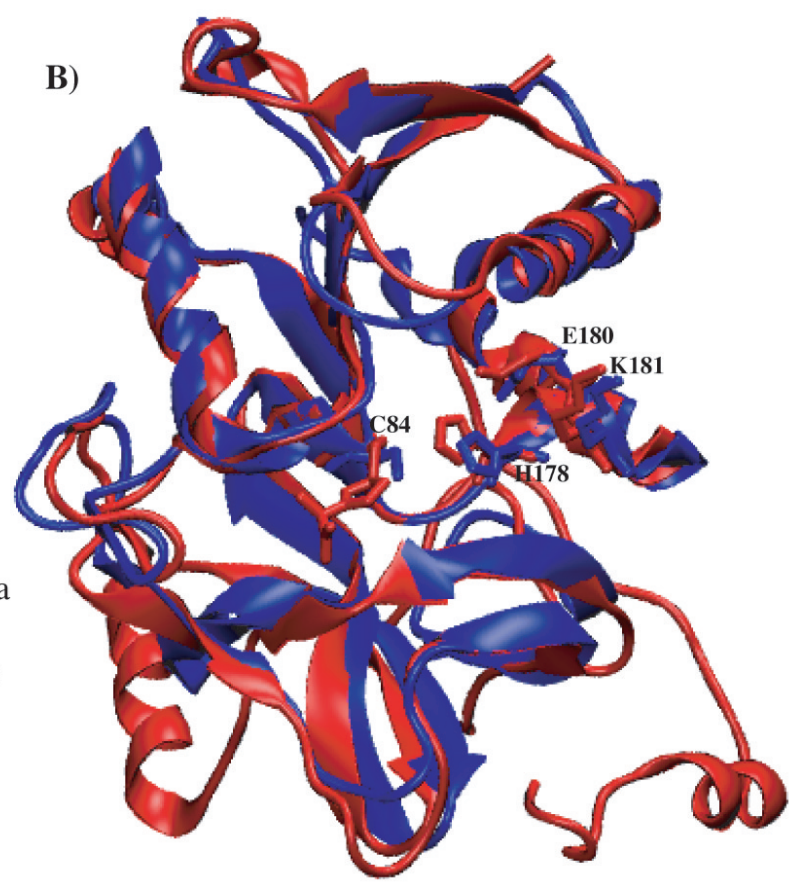

Figure 12: Evolutionary analysis of hisH 

X. fastidiosa
B. aphidicola
M. leprae
S. epidermidis
S. elongatus
T. maritima
S. cerevisiae
A. thaliana
E. nidulans
M. thermoautotrophicus

R5 D1

--MLSRRLIPCLDVR $\frac{\text { K19 }}{19}$ KGVKFRDE46 MYSG------NGLAVRVIPCLDVY-----CGRVVKGVNFKN-----------LRDAGDLVELAAAYDAEGADELAFLDVTASSSG---RA -----------MIKKRVIPCLDVK-----DGRVVKGIQFQS-----------LRDIGNPVDLALYYNEAGADELVFLDISKTEAG---HD ---------MMLAKRILPCLDVK-----AGRVVKGVNFVN-----------LRDAGDPVELAQAYNAAGADELVFLDITATHEE---RN ---------MLAKRI IACLDVK-----DGRVVKGTNFEN-----------LRDSGDPVELGKFYSEIGIDELVFLDITASVEK----RK ------DYSNYGLTRRI IACLDVRTNDQGDLVVTKGDQYDVREKS---DGKGVRNLGKPVQLAQKYYQQGADEVTFLNITSFRDCPLKDT --------KASKLAKRVIACLDVRTNDKGDLVVTKGDQYDVREQS---NENEVRNLGKPVDLAGQYYKDGADEISFLNITGFRDFPLGDL --------EKNGLTRRI IACLDVRTNDVGDLVVTKGDQYDVREKDGADAGGQVRNLGKPVDMAKKYYEQGADEVTFLNITSFRNCPLADL -----------MLAKRI IPCLDCDLQV-PNGRVVKGVEFKQ-----------IRYAGDPVELATRYYEDGADEIVFLDITASHER---RE $: *::{ }^{* * *}$ *.**: : *. * :. * * **: * : :

P76 T78 D98 K99 T104

Q123 VDYRWVERVARLIDIPFCVAGGIGQVET-----------ARAVLHAGADKISINSPALRQPA-------------LISALAEAFGVQCVV VDRSWIKNVSKVINIPFCVAGGIKSVED------------AKKVLSSGADKISINSSALIDPN--------------LITKISERFGVQCVV TMLEVVRCTAEQVF IPLMVGGGVRTVAD------------VDVLLRAGADKVAVNTAAIARPE--------------LLADMAGQFGSQCIV LMIEVIEATAKQLFIPLTVGGGIONLDD-----------ITQLLNHGADKISLNSSALKHPE-------------LIRQASEKFGROCIC ILIDVVYRTADQVF IPLTVGGGIQSLTM------------IKDLLRAGADKVSLNSAAVRQPD--------------LVNQASDRFGAQCIV TMLELVEKVAEQIDIPFTVGGGI HDFET-----------ASELILRGADKVSINTAAVENPS-------------LITQIAQTFGSQAVV PMLEVLKQAAKTVFVPLTVGGGIKDIVDVDGTKIPALEVASLYFRSGADKVSIGTDAVYAAEKYYELGNRGDGTSPIETISKAYGAQAVV PMIQVLRQTSKNVFVPLTVGGGIRDFTDASGRYYSSLEVAAEYFRSGADKISIGSDAVSAAEEF IKSG-VKTGKSSLEQISRVYGNQAVV PMLEILRRTSETVFVPLTIGGGIRDTVDTDGTHIPALDVASMYFKSGADKVSIGSDAVVAAEDYYAAGKVLSGKTAIETISKAYGNQAVV TMTHVIEATTENVFVPICVGGGIRKPED-----------YFKMLKAGADKCSTNTAAIKNPE-------------LINEASDLVGSQACV

$: \quad: \quad::^{*}::^{* *}:$

D130

VGIDSIRE- $: * * *: . \mathbf{A}^{*}:$.

E167

D176

X. fastidiosa

B. aphidicola

M. leprae

S. epidermidis

S. elongatus

T. maritima

S. cerevisiae

A. thaliana

E. nidulans

M. thermoautotrophicus IGIDSWFDK--------------------TKNSYMVQQYTGDISKTYQTSWKTSDWVKKVQEKGAGEIVLNMMNKDGLQKGYDISHLS LSVDARTVPTGSA-----------------RTPSGWEATTHGGYRG-----TGIDAVEWAARGADLGVGEILLNSMDADGTKAGFDLAMLR

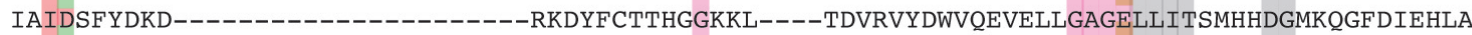
VAIDARREPDCA-----------------PDQPRWQVYVRGGREA----TGLDAVAWAVEMAKRGAGELLVTSMDADGTQAGYDLELTR VAIDAKRVD-----------------------GEFMVFTYSGKKN----TGILLRDWVVEVEKRGAGEILLTSIDRDGTKSGYDTEMIR ISVDPKRVYVNSQADTKNKVFETEYPGPNGEKYCWYQCTIKGGRES----RDLGVWELTRACEALGAGEILLNC-DKDGSNSGYDLELIE VSIDPRRVYVNHPDDVPYKVIRVTNPGPNGEEYAWYQCTVSGGREG----RPIGAFELAKAVEELGAGEILLNCIDCDGQGKGFDIDLVK VSVDPKRVYVSOPEDTKHRTIETKFPNAAGQNFCWYQCTIKGGRET----RDLDVCQLVQAVEAMGAGEILLNCIDKDGSNSGSILTDQP VAIDAKRRYIENPRESDERFIIEV----DDG-YCWYECSIYGGREF----TGIDAVKWAMECQDRGAGEILLTSMDRDGTKMGYDIPLTR :. : *.

S201
QARALCQ-VPLVASGGAGNMOHFADVFHKADVDGALAASVFHSGAILIPGLKQFLREQQIEVRDVEIRKICK-VPLIASGGAGSVEHFYEALYYSNVDGVLAASVFHKNIVEIKVLKKKLIARGMEIREC---AVRAAVT-VPVIASGGAGAIEHFVPAVTAG-ADAVLAASVFHFRELTIGOVKDAMAAAGIAVR-KIKQLVN-IPIIASGGGGNAQHFVELFQQTDVSAGLAASILHDQETTVAEIKDKMREGGILVRAIAERVE-IPVIASGGAGTCEHIRAALVEGKAEAALLASLLHYGQLTIAQIKGYLHOHOVPVRQAEPLPQPAREGLGDSARRAMSSG FVRPLTT-LPI IASGGAGKMEHFLEAFLAG-ADAALAASVFHFREIDVRELKEYLKKHGVNVRLEGL-------------------HVKDAVK-IPVIASSGAGVPEHFEEAFLKTRADACLGAGMFHRGEFTVNDVKEYLLEHGLKVRMDEELISDSVG-IPVIASSGAGTPDHF SEVFEKTNASAALAAGIFHRKEVPIQSVKEHLQEERIEVRI-PSKRAVK-IPVIASSGAGMPKHFEEVFDQTTTDAALGAGMFHRGEYTVGEVKOYLEDRGFLVRRFEPDVTMSENLD-IPVIASGGVGEPEHIYEAFTDGKADAALAAS IFHFNEYPVPAVKEYLRSRGVPIRL-

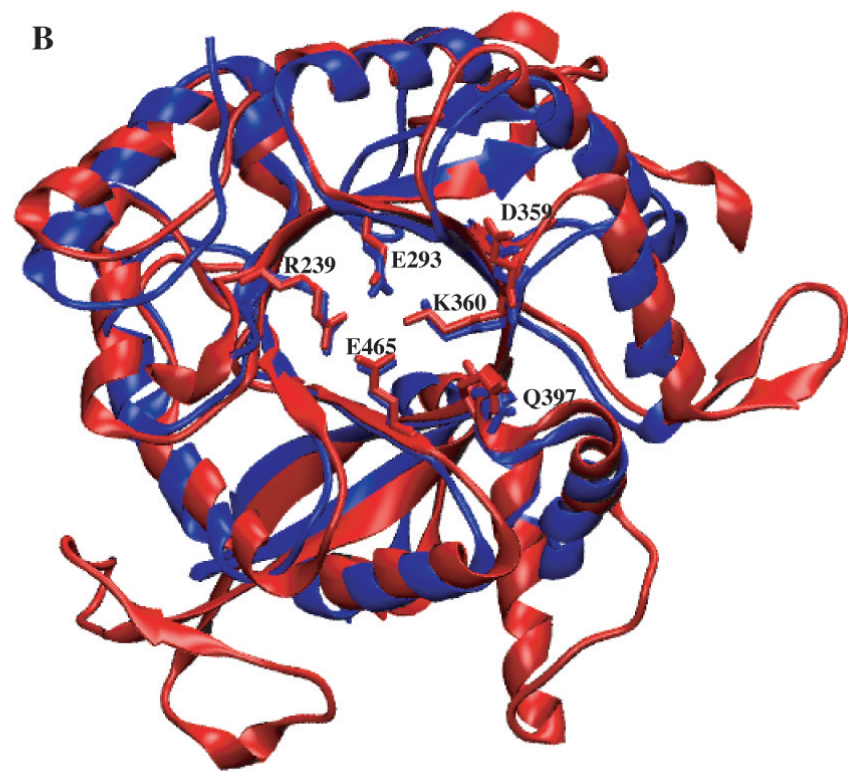

Evolutionary profile of synthase domain and structural alignment.

A) Representative alignment from sequence QR method (1) shows bacteria (blue), eukarya (red), and archaea (green). All available Swiss-Prot sequences of hisF were aligned and then ranked by sequence dependence; $S$. cerevisiae (yeast) and T. maritima were constrained to be the first two in the ordering. Strict conservation is denonted with an * and partial conservation by either ":" or ".". Residues predicted to play a role in the allosteric effect are highlighted according to the color scheme in Figure 1, catalytic and allosteric in green, and residues involved in the ammonia transfer process and allosteryin orange. Experimentally mutated residues are underlined.

B) Structural alignment of yeast (red) and T. maritima (blue) crystal structures indicates high structural homology between the two isoforms, despite insertions in yeast. ${ }^{\circ}$ Conserved residues are shown in licorice, and the overall RMSD is $1.57 \mathrm{~A}$.

1. A. Sethi, P. O'Donoghue, and Z. Luthey-Schulten, "Evolutionary profiles from the QR factorization of multiple sequence alignments," PNAS, 102 (2005) 4045 - 4050. 


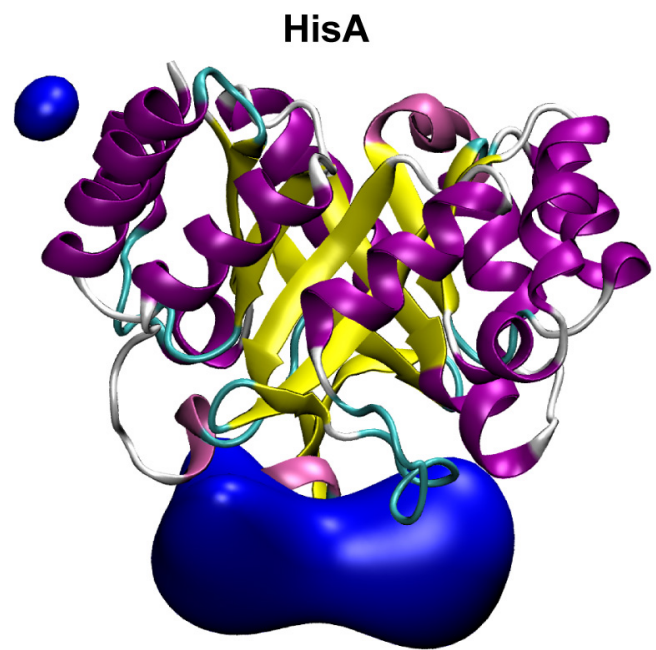

Electrostatically symmetric 5'-ProFAR docking site

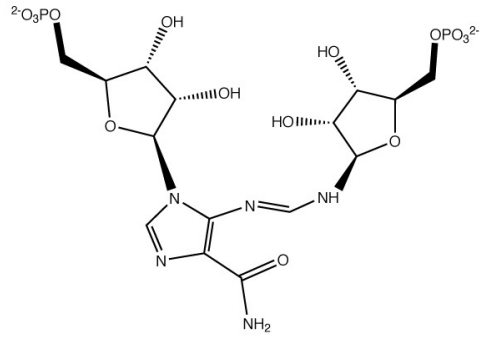

5'-ProFAR

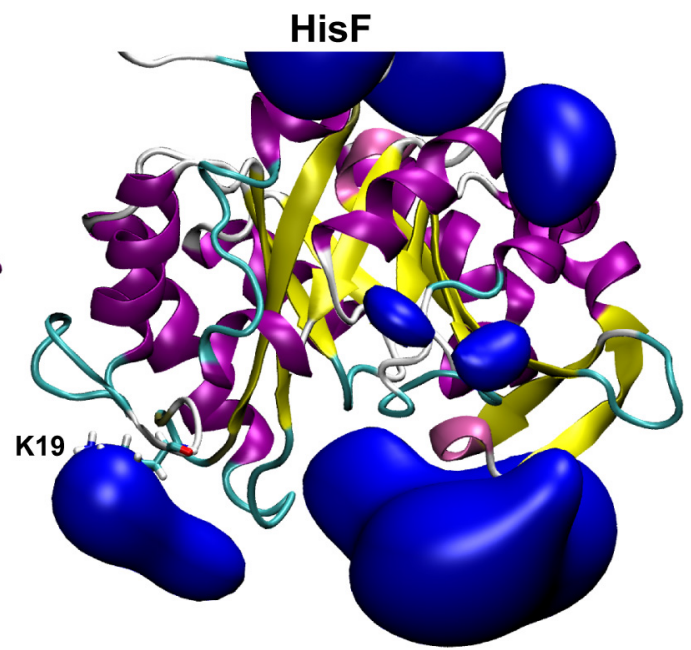

Electrostatically asymmetric PRFAR docking site<smiles></smiles>

PRFAR

Figure 14: Electrostatic potentials guide docking of barrel substrates. Positive electrostatic potentials (depicted as blue lobes) at the C-terminus ends of hisA and hisF steer the binding of the symmetric and asymmetric 5'-ProFAR and PRFAR substrates, respectively. The electrostatic potential in hisA is drawn at $113 \mathrm{kT} / \mathrm{e}$ and $45 \mathrm{kT} / \mathrm{e}$ for hisF. 
A)
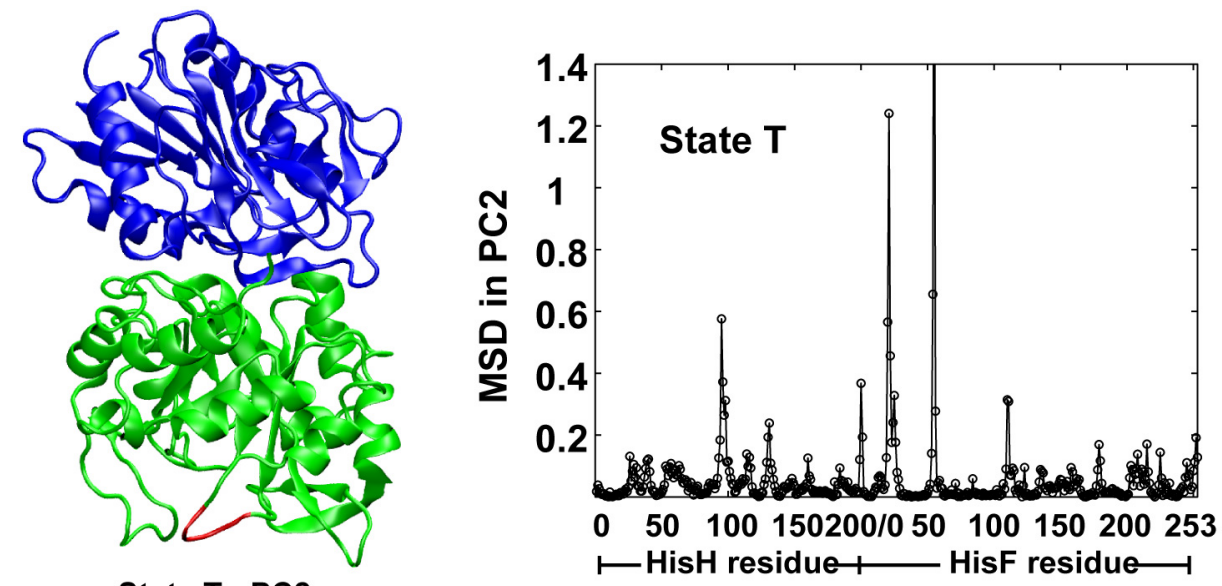

State T - PC2

B)
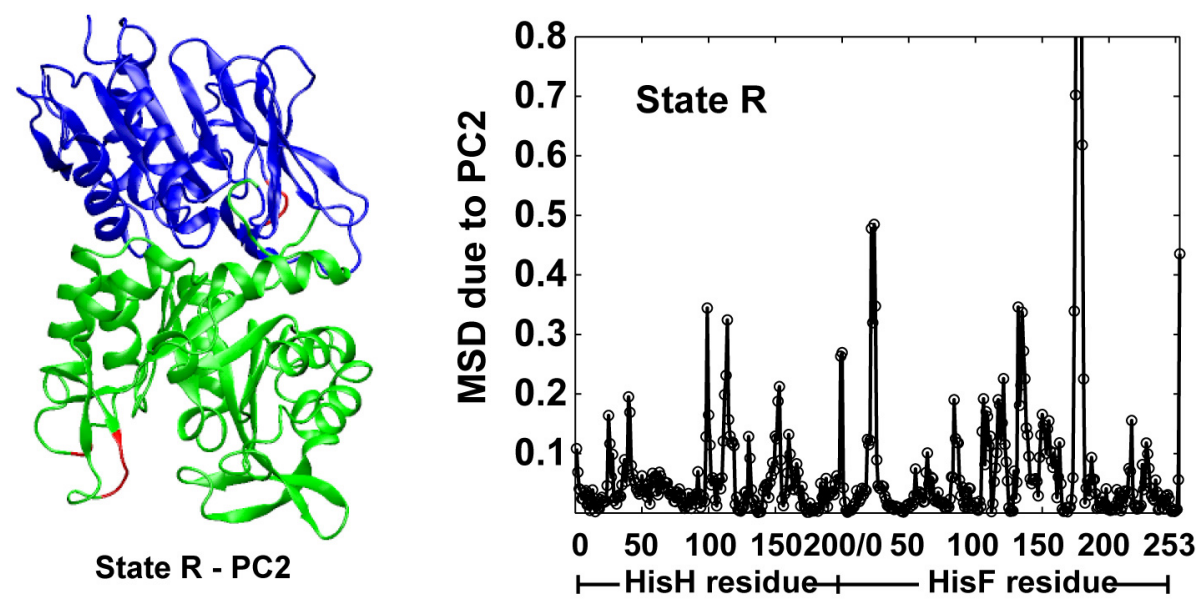

Figure 15: Motion due to Principal Component 2. The mean square deviation per residue for motion due to $\mathrm{PC} 2$ in state $\mathrm{R}(\mathrm{A})$ and state $\mathrm{T}(\mathrm{B})$ are shown. The residues which have the largest MSD due to $\mathrm{PC} 2$ are shown as red on the protein complex. 

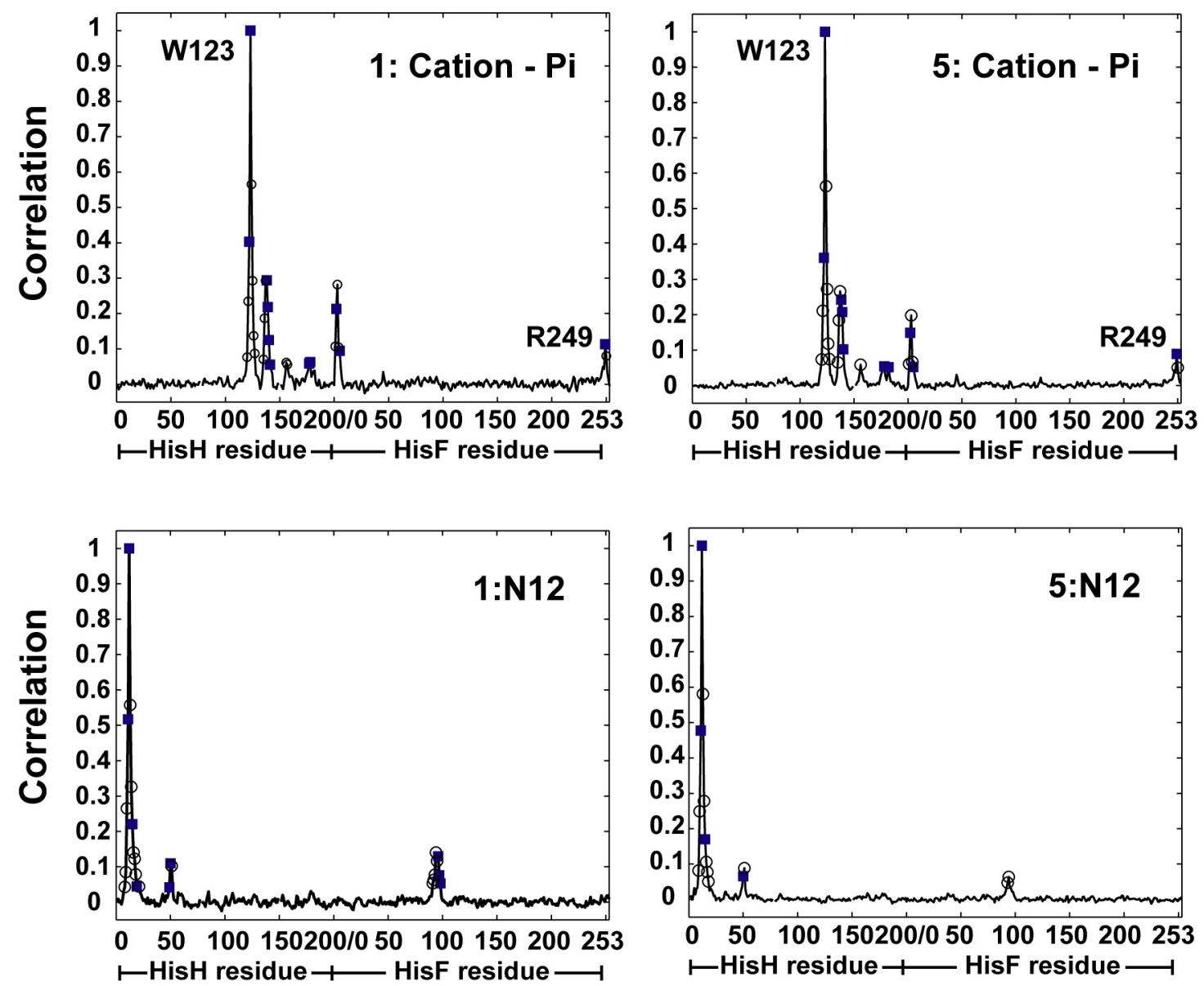

Figure 16: Correlation at the interface. Correlation of the conserved residues $h \mathrm{~W} 123$ in time segment 1 (A) and time segment $5(\mathrm{~B})$ and $h \mathrm{~N} 12$ in time segment 1 (C) and time segment 5 (D) are shown. $h \mathrm{~W} 123$ forms a cation-pi with $f$ R249 and this interaction remains correlated throughout the simulation while $h$ N12 forms a hydrogen bond with $f$ G96 which becomes weaker as PRFAR is undocked. 